at Mount Morris, New York, of English parents who had emigrated to the United States in 1830, Powell was educated at Illinois and Oberlin College. $\mathrm{He}$ served in the army during the Civil War, losing an arm at the battle of Shiloh, and in 1865 became professor of geology in the Illinois Wesleyan University at Bloomington. Two years later he began a series of hazardous and important expeditions to the Rocky Mountains and the Green and Colorado Rivers, which led to a Government geographical and geological survey of the Rockies. Powell served on this for several years and his reports, together with those of F. V. Hayden and G. M. Wheeler, were embodied by Clarence King in the United States Geological Survey bulletins. In 1879 Powell was made director of the United States Bureau of Ethnology, and in 1881, on the resignation of King, he became also director of the Geological Survey. He held the latter post for thirteen years, but retained the former until his death at Haven, Maine, on September 23, 1902. Powell was one of those pioneer geologists of the Far West, who as von Zittel said, "by their vivid portrayal of the work of subaerial denudation . . roused the intellectual life of the middle of the century to new conceptions on a grand scale".

\section{The Electron in Electrical Engineering}

Mr. C. C. Paterson gave on March 15 the Faraday lecture to the Institution of Electrical Engineers, choosing as his subject "The Electrical Engineer and the Free Electron". It was the kind of lecture that one could have imagined Faraday himself to have given, consisting of lucid explanations and practical demonstrations of fundamental principles. $\mathrm{Mr}$. Paterson stated that the science of electrical engineering was born again when the physicist showed how electricity could be liberated from metal. In the free state it has potentialities of which no one dreamed before its discovery by Sir J. J. Thomson. Just as physiologists learned that disease can be envisaged in terms of isolated germs and their life-history, so the physicist found that electricity can be thought of in terms of the individual electron, its habits and affinities. Two of the main reasons for the practical usefulness of electricity are the ease with which it can be transported and the ease with which it can be controlled. In the latter respect the free electron has now given the engineer new and extraordinary power. Many applications have been already revo. lutionised and there are doubtless many more surprises in the future. The secret is that a stream of free electrons, whether in a vacuum or a gas, can be manipulated with such facility that the electrical energy output can be reversed at the rate of millions of times a second. Alternatively, it can be made to fluctuate at any given slow speed. While the agency which imposes this control on the electron stream is usually itself electrical, it is possible to control it by light, magnetism or heat.

Normally the electrons are confined within metal conductors. When a portion of a circuit (a thermionic valve cathode or filament) is heated, electrons emerge freely, like water pouring through a porous section of hose pipe. Heat is the agent which liberates the electrons from the interior of the wire. They swarm in a thin layer round the outside surface, ready to be attracted away by externally applied electrical forces exerted by another metal electrode. As the electrons travel between the electrodes, the control causes them to flow or ebb, reverse or oscillate. Frequencies up to 3,000 million per second are attainable. The photoelectric cell is another liberator of electrons. In this case they emerge from a sensitised cold surface (cathode) where light falls on it, and are collected on the anode. These cells are capable of receiving more than 300,000 impulses per second. Mr. Paterson explained and demonstrated the way in which sound and speech are reproduced in various devices. He said that the electron often behaves as if it were a solid particle, but under other conditions it appears to be a group of waves. It acts the same whether it has the particle or the wave characteristics. In free space it acts like waves, but when it collides with something it has particle characteristics. The filament of the incandescent lamp causes the electrons to crowd together and this heats it so much that it gives out light. If the electrons escape from the filament its light-giving properties deteriorate, but if the gas envelope is filled with suitable gas mixtures, the escaping electrons collide with the gas atoms and produce a brilliant and highly efficient light source. This is the principle utilised in luminous gas discharge tubes. Cold cathode tubes need a high voltage to induce the electron stream, but a hot cathode produces a much more copious stream and enhances the brightness of the light. Some of these luminous tubes produce twice as much light as an ordinary filament lamp taking the same power.

\section{Excavations at $\mathrm{Ur}$}

OwINg to the late date at which excavations were resumed at Ur this year, Dr. C. L. Woolley's first report on the season's work has only just been received and is published in the Times of March 16. The operations of the joint expedition this year are to be directed to the exploration of a cemetery of the Jemdet Nasr period of about 4,000 B.c., which lies at a depth of $54 \mathrm{ft}$. below the surface and involves the removal of about 5,000 tons of accumulated rubbish. 'The three weeks' work which had been completed at the time Dr. Woolley wrote has produced a remarkable example of sculpture in the round in the form of a woman's figure in alabaster with lapis lazuli inlay forming a fillet outlining the face, lapis lazuli and shell eyes, bituminous inlay for the eyebrows, which meet above the nose, and hair in dark paint. The statue is ten inches high. It is not only the earliest known example of sculpture in the round at Ur, dating from about the last quarter of the fourth millennium, but it is also remarkable as being the first statue to be found in a grave. It lay in a soldier's grave, close to his head and touching the blade of a bronze axe which he carried over his shoulder. This grave is situated in what would appear to have been a military cemetery in the latter 